Running head: CAREER DOUBT IN A DUAL-DOMAIN MODEL OF GOAL PURSUIT

Career Doubt in a Dual-Domain Model of Coping and Progress for University Students' Academic and Career Goals

Melodie Chamandy and Patrick Gaudreau

University of Ottawa

This pre-print is currently under review and will likely change during the review process. This is not the copy of record and will not exactly replicate the final authoritative published version.

Version 2 - June 2018

\title{
Acknowledgement
}

This research was supported by a doctoral scholarship from the Social Sciences and Humanities Research Council (SSHRC) awarded to the first author. Special thanks to everyone in the Laboratory for Research on Achievement, Motivation and Regulation of Action (Alexandre Gareau, Kristina Kljajic, Laurence Boileau-Perreault, and Ben Schellenberg) whose daily conservations and feedback have contributed to the refinement of this manuscript. 


\begin{abstract}
University students set career goals during their academic journey in order to facilitate their transition to the labor market. Career goals can nonetheless be accompanied by doubt, even among the most determined students. The purpose of this cross-sectional study $(N=234)$ was to investigate the role of career doubt on the progress made by university students in the simultaneous pursuit of their academic and career goals. We examined the mediating role of academic and career coping strategies in the relationship between career doubt and academic and career goal progress. The results from structural equation modeling revealed a significant indirect effect of task-oriented coping in the relationships between career doubt and both career progress and academic progress. Although career doubt was positively and significantly associated with disengagement-oriented coping for academic and career goals, the indirect effect of disengagement-oriented coping was not statistically significant. Overall, these results clarify the mechanisms by which university students pursue their goals as a preliminary effort to inform practitioners about the role of coping to better prepare students for a successful transition to the labor market.
\end{abstract}

Keywords: Career goals; academic goals; career doubt; goal progress; coping. 


\section{Career Doubt in a Dual-Domain Model of Coping and Progress for University Students' Academic and Career Goals}

Post-secondary education is a time that requires students to carefully select and pursue the academic and career goals that will provide the foundation for their future professional achievements (Arnett, 2000; Chickering \& Reisser, 1993; Erikson, 1968; Praskova, Creed, \& Hood, 2015; Shulman \& Nurmi, 2010). Students may nonetheless experience increased pressure, stress, and doubt regarding their career choices and commitments (Porfeli \& Savickas, 2012). These challenges can affect not only their academic and professional achievements, but also their short- and long-term psychological adjustment (Dietrich, Jokisaari, \& Nurmi, 2012; Lent, Brown, \& Hackett, 1994; Porfeli, Lee, Vondracek, \& Weigold, 2011; Sheldon \& Elliot, 1999). As such, the coping strategies used by students to manage these challenges may explain why certain students are making greater progress toward the achievement of their academic and career pursuits (Aldwin, Skinner, Zimmer-Gembeck, \& Taylor, 2011). To date, however, no research has attempted to examine how career doubt and coping with academic and career pursuits operate to predict students' success in both of these age-normative achievement domains. In this study, we investigated how students are coping in their academic and career endeavors, respectively, in order to explicate why career doubt can impede the subjective progress that students are making in the pursuit of both their academic and career goals.

\section{Career Doubt and Goal Progress}

Post-secondary education is a time when young adults explore their self and their external environment to gain a deeper understanding of their personal values, abilities, and aspirations (Chickering \& Reisser, 1993). This period of exploration can serve to facilitate effective academic and career goal pursuit by guiding the formation of career-relevant interests (Lent et al., 1994; 
Savickas, 1999; Shulman \& Nurmi, 2010). More importantly, career decisions are among the few with meaningful, often lifelong, consequences. The importance of these decisions can produce doubt in even the most decisive students. Career doubt is therefore not a matter of choosing between different career options (i.e., career indecision), but rather a specific feeling about choices that have already been made. This doubt can be defined as a component of vocational identity that represents feelings of anxiety and uncertainty regarding career choices and commitments (Porfeli et al., 2011; Porfeli \& Savickas, 2012). These negative thoughts or feelings (e.g., anxiety, uncertainty) about a specific situation, in turn, have been found to relate to avoidance behavior (Ozer \& Bandura, 1990). From the viewpoint of expectancy - value models (Carver \& Scheier, 2001; Wigfield \& Eccles, 2000), individuals who are doubtful are less likely to take action. Doubt can impair effort both before the action begins and while it is ongoing. Accordingly, the theory proposes that when people have confidence about an eventual outcome, they remain engaged and their efforts continue, even in the face of adversity (for a review, see Carver, 1998). Furthermore, Bandura (1994) portrayed doubt - a factor that hinders effort, persistence, and behavior in the face of difficulties - as being the opposite of self-efficacy. Hence, doubt is believed to hinder coping and achievement, much like self-efficacy has been shown to foster coping and achievement in the goal striving process (Bandura, 1994; Carver \& Scheier, 2001; Schunk, 1990). A number of studies have supported these assertions in the context of goal pursuit, while doubt has yet to be examined (Locke, Frederick, Lee, \& Bobko, 1984; Zimmerman, Bandura, \& Martinez-Pons, 1992). Based on these considerations, we proposed that career doubt - the doubt one feels regarding self-set career goals - would play a pivotal role in goal pursuit processes and outcomes (Bandura, 1989; Locke, 1996; Brandstätter \& Herrmann, 2016).

Thus far, researchers have yet to examine the specific link between career doubt and 
indicators of achievement. However, research on career indecision and goal commitment - similar but distinct psychological constructs - provides good anchor points to propose that career doubt should relate to the achievement of students. Hence, we used this literature to inform the development of our hypotheses regarding career doubt. In particular, studies have found that career indecision negatively relates to objective academic achievement (Lunneborg, 1975, 1976; Spitzer, 2000; Walters, 1982) and retention (Cuseo, 2005; Gordon \& Steele, 2015). Despite this supportive evidence, researchers have sometimes observed weak associations between career indecision and the grade point of average of students (Kahn, Nauta, Gailbreath, Tipps, \& Chartrand, 2002). Grade point average remains a widely used measure to benchmark students and make important administrative decisions (e.g., admission, probation, bursaries). Such measures, however, typify the cumulative achievement taken at the end of a period (e.g., semester, year) and do not take into consideration the idiosyncratic nature of the personal goals pursued by each student. Furthermore, students can pursue both academic and other developmentally important goals - such as career goals - and the progress they make outside of the academic domain remains unmeasured through typical objective measures of academic achievement. Goal progress, which can be studies across life domains, offers a useful level of analysis to understand the personal and subjective progress students feel they are making toward the attainment of their personal goals (Wiese, 2007). We therefore turned to a subjective measure in order to broaden our analysis of the relationship between career doubt and the subjective success of students in the pursuit of both their academic and career goals.

\section{Career Doubt, Coping, and Progress on Developmental Goals}

The simultaneous pursuit of academic and career goals involves many challenges (Higgins, Loeb, \& Ruble, 1995). One such challenge that is particularly salient in the context of 
career pursuits pertains to the way individuals perceive and respond to uncertainty and change (i.e., ambiguity tolerance; Xu \& Tracey, 2014). Coping strategies, which are often typified as self-regulation under stress (Compas et al., 2014), represent the behavioral and cognitive efforts to manage specific external and internal demands that are appraised as taxing or exceeding the resources of the person (Lazarus \& Folkman, 1984). According to the transactional model of stress and coping developed by Lazarus and Folkman $(1984,1987)$, coping responses aim to reduce the gap between demands and available resources, and thereby diminish perceived stress and any associated negative emotions. Importantly, coping strategies not only serve in response to traumatic events, but also in the pursuit of developmental goals that typically involve many day-to-day challenges and opportunities for long-term growth (Amiot, de la Sablonnière, Terry, \& Smith, 2007; Heckhausen et al., 2010; Skinner \& Wellborn, 1997). Coping strategies can be divided into two coping dimensions, reflecting persistence with goal-directed effort (i.e., taskoriented) or withdrawal from goal-directed effort (i.e., disengagement-oriented; Carver \& Connor-Smith, 2010; Lazarus, 2006). On the one hand, task-oriented coping involves strategies aimed at actively managing the source of stress and the resulting thoughts and emotions, such as creating a plan of action or seeking advice. On the other hand, disengagement-oriented coping involves strategies aimed at disengaging or distracting the self from the source of stress, such as venting negative emotions or going to the movies.

While there has not been much research on the specific link between career doubt and coping, the career development literature has focused on other aspects of career choice, such as career calling, career identity, and career indecision. To illustrate the hypothesised link between career doubt and coping, we turn toward empirical findings relating to these variables as a proxy to present the rationale behind our proposed model. Specifically, career calling has been found to 
act as an important personal initiator of goal-related effort and action, including the ability to adapt to unforeseen change (Praskova, Creed, \& Hood, 2014). Moreover, Fugate, Kinicki, and Ashforth (2004) proposed that career identity acts as a cognitive map that directs and motivates individuals to actively adapt to challenges in order create opportunities that match their aspirations. Students with a stronger career identity are also more likely to pursue goals that are motivating and that give them a sense of purpose (Chickering \& Reisser, 1993). Motivating goals, in turn, have been shown to trigger task-oriented coping strategies in achievement-related settings such as university (Amiot, Blanchard, \& Gaudreau, 2008; Gaudreau, Carraro, \& Miranda, 2012) and work (van Dierendonck, 2015). More specific to the context of this research, students who exhibit greater career indecision have been found to use significantly more forms of avoidant coping strategies (e.g., disengagement-oriented) and significantly less forms of active coping strategies (e.g., task-oriented) in the context of career decision-making (O'Hare \& Beutell, 1987; O’Hare \& Tamburri, 1986). Further, career doubt has been shown to relate negatively to affective, behavioral, and cognitive engagement among undergraduate students (Wong \& Kaur, 2018), which further supports the link between career doubt and the selfregulatory processes involved in task-oriented coping. Together, these findings provide the foundation to suggest that career doubt may be linked to different types of coping strategies in response to academic- and career-related goal demands. Based on these accounts, we propose that students who experience higher levels of career doubt may be more likely to use disengagementoriented coping strategies, whereas students who experience lower levels of career doubt may be more likely to engage in task-oriented coping strategies to overcome the daily demands and obstacles associated with their goals.

Coping largely influences goal-related behavior as it provides the motivational, cognitive, 
and behavioral efforts to manage stressful internal and external demands and create the conditions that allow one to progress toward desired outcomes (Carver \& Scheier, 2000; Lazarus, 2006). Empirical evidence has highlighted the relationship between coping strategies and achievement in different settings (Amiot et al., 2004; Brown, Westbrook, \& Challagalla, 2005; Gaudreau et al., 2012). In particular, task-oriented coping responses have been shown to relate positively to prospective academic goal progress (Gaudreau et al., 2012) as well as objective indicators of academic achievement (e.g., Edwards \& Trimble, 1992; Saklofske, Austin, Mastoras, Beaton, \& Osborne, 2012) and subjective indicators of job performance (Shimazu \& Schaufeli, 2007; Shimazu, Schaufeli, \& Taris, 2010). More recent research has also revealed that task-oriented coping in response to career uncertainty was associated with a higher chance of finding a job over one year (Körner, Lechner, Pavlova, \& Silbereisen, 2015). In support of these findings, metaanalytic efforts have revealed the benefits of interventions aimed at increasing the use of active coping strategies, such as implementation planning, for goal progress (Koestner, Lekes, Powers, \& Chicoine, 2002) and goal achievement (Gollwitzer \& Sheeran, 2006). However, there have been mixed findings regarding the link between disengagement-oriented coping and achievement. Some researchers have found disengagement-oriented coping to relate negatively to measures of academic goal progress (Gaudreau et al., 2012), academic performance (MacCann, Fogarty, Zeidner, \& Roberts, 2011), and job performance (Shimazu \& Schaufeli, 2007), whereas other researchers have not (Gaudreau et al., 2012; Körner et al., 2015; Saklofske et al., 2012; Shimazu, Schaufeli, \& Taris, 2010). Further, disengagement-oriented coping in response to career uncertainty has been shown to predict a lower income, but not job attainment (Körner et al., 2015). Overall, coping strategies are associated with achievement in both the academic and career domains, although researchers have yet to examine the role of coping in the progress made by 
university students in the simultaneous pursuit of their academic and career goals.

\section{The Present Study}

University students set career goals during their academic years in order to facilitate their transition to the working world. It is not uncommon for students to experience doubt regarding their career choices, which may ultimately play a role in their academic and career achievements (Akkermans, Nykänen, \& Vuori, 2015; Shulman \& Nurmi, 2010). Given that the selection and pursuit of academic and career goals is accompanied by many important decisions and challenges (Nurmi \& Salmela-Aro, 2002), coping usage is expected to act as an important mediator of the complex goal-outcome relationship (Amiot et al., 2004; Gaudreau et al., 2012; Nurmi, SalmelaAro, \& Koivisto, 2002; Struthers, Perry, \& Menec, 2000). As such, students with greater career doubt may be less likely to use the coping strategies associated with academic and career goal progress.

In this study, we proposed and tested a dual-domain model in which we tested the mediating role of academic and career coping in the association between career doubt and goal progress for academic and career goals. We first hypothesized that career doubt would be negatively associated to both academic and career goal progress. In analytical parlance, we expected career doubt to have a significant total effect on academic and career goal progress (i.e., when not controlling for coping). Furthermore, we hypothesized that career doubt would be negatively associated to academic and career task-oriented coping (TOC) and positively associated to academic and career disengagement-oriented coping (DOC). We also hypothesized that academic TOC and career TOC would be positively associated to academic and career goal progress, respectively. In contrast, academic DOC and career DOC were hypothesized to be negatively associated to academic and career goal progress, respectively. Based on our proposed paths, we also explored the mediating 
role of coping in the association between career doubt and goal progress. In clear, we expected the direct effects between career doubt and academic and career goal progress to become nonsignificant in a model controlling for the role of academic and career coping. As a corollary, we hypothesized significant indirect effects for the associations between career doubt and academic and career goal progress by means of academic and career TOC and DOC.

The academic and career goals of university students are interrelated on many grounds (Lent, Brown, \& Hackett, 1994; Sun \& Frese, 2013). On the one hand, coping efforts invested in the pursuit of one goal may facilitate or hinder the progress made in the pursuit of the other goal (Wiese \& Salmela-Aro, 2008). On the other hand, individuals orient their coping efforts toward the specific demands of a particular goal or life situation. Therefore, coping used in the context of a particular developmental goal may be limited to specialized within-domain effects rather than generalizable between-domain effects. For that matter, we compared two alternative models to consider these viewpoints on the nature of coping. In the first model, we proposed a within-domain effect, in which coping in a goal domain relates to goal progress in the corresponding domain (e.g., paths from academic coping to academic goal progress). In the second model, we proposed a crossdomain spillover effect in which coping in a goal domain not only relates to goal progress in the corresponding domain, but also to goal progress in the other goal domain (e.g., paths from academic coping to career goal progress and from career coping to academic goal progress).

\section{Method}

\section{Participants and Procedure}


A total of 253 undergraduate students (164 first-year and 89 fourth-year students) from a Canadian university participated in the study. Participants were recruited in class ${ }^{1}$ and through an online research participation system ${ }^{2}$. The study was approved by a university research ethics committee and comprised of an online questionnaire that participants completed during the fall semester of 2015. Of the 253 participants, 19 participants were outliers or had missing data and were therefore excluded from the analyses ${ }^{3}$. The final sample $(\mathrm{N}=234 ; 70 \%$ female $)$ ranged from 17 to 30 years $(M=20, S D=2.29)$. Participants were ethnically diverse, with $54.4 \%$ Caucasian, 9.3\% African Canadian, 16.5\% Asian Canadian, 7.2\% Arabic, and 12.6\% "Other". Ninety-three percent of students were enrolled full-time (i.e., four classes or more) in various faculties, such as Arts (10\%), Engineering (4.4\%), Health Sciences (28.4\%), Science (16.8\%), Social Sciences (38\%), and School of Management (2.4\%). Approximately $41.4 \%$ of students received full financial support from their parents during their studies, while $33.3 \%$ received partial support, and $25.3 \%$ received no support. Forty-six percent of students reported working outside of school for an average of 15 hours per week. All participants provided written informed consent prior to participating in the study.

\section{Measures}

Personal Goals. Participants reported an important and specific goal they wished to pursue in each of the academic and career goal domains. Asking participants to report both an

\footnotetext{
${ }^{1}$ Participants who were recruited in class received a 5 \$mazon.ca gift card.

${ }^{2}$ Participants who were recruited through the online research participation system were offered one participation point in their introductory psychology course.

${ }^{3}$ Further information about exclusion of participants is provided in the result section.
} 
academic and career goals favored consistency throughout the questionnaire by allowing us to assess domain-specific coping and domain-specific goal progress based on these goals. The two goals provided a reference point for students to evaluate their own progress and coping responses. We provided no specific timeframe for the pursuit of their goals given that students were at different stages in their undergraduate studies. Goals were defined as projects and concerns that people think about, plan for, carry out, and sometimes (though not always) complete or succeed at (Koestner, Otis, Powers, Pelletier, \& Gagnon, 2008). Participants reported goals such as “Obtaining a $\mathrm{PhD}$ in psychology" (i.e., academic) and "Become a professor" (i.e., career); "Increase my average by at least 0.2 points this semester" and "Become a lawyer and be hired at a reputable firm"; "I am hoping to maintain a GPA of at least 9 on 10 this semester and next semester" and "Pursuing a career in medicine."

Career doubt. Career doubt was measured with the career self-doubt subscale of the Vocational Identity Status Assessment (Porfeli et al., 2011). This subscale includes five items using a scale from 1 (Do not agree at all) to 5 (Totally agree). The scale assesses the extent to which participants doubted their career choice, with higher scores reflecting greater doubt, uneasiness, and worry about one's career choice and a sense that others share the same feelings and ideas about their choices. Sample items were as follow: "I may not be able to get the job I really want" and "When I tell other people about my career plans, I feel like I am being a little dishonest". Score reliability of each subscale was examined with coefficient $H$ (Hancock \& Mueller, 2001). Coefficient $H$ is a measure of construct reliability computed from the standardized factor loadings estimated in confirmatory factor analyses. Consistent with previous studies (e.g., Porfeli \& Savickas, 2012), the reliability of this measure in the current sample was adequate, with standardized loadings ranging from .63 to $.79(H=.84)$. 
Goal progress. Perceived goal progress for academic and career goals were respectively measured with five items using a scale from 1 (Not at all) to 7 (Totally). Sample items were as follow: Please rate the extent to which "you progressed on your goal", "you moved forward in the pursuit of your goal”, and "you came closer to reaching your goal” (Carraro \& Gaudreau, 2015). Consistent with previous studies (e.g., Carraro \& Gaudreau, 2011), goal progress had excellent reliability in this sample, with standardized factor loadings ranging from .90 to $94(H=.97)$ and .81 to $92(H=.95)$ for academic and career goal progress, respectively.

Coping. Coping with the demands of academic and career goal pursuit were respectively measured with The Coping Inventory for Academic Striving (CIAS-22; Thompson, 2015), which was also adapted to the career goal domain for the purpose of this study. The inventory was composed of 22 items measuring 7 coping strategies organized within task-oriented coping (TOC; i.e., planning, logical analyses, thought control, positive reappraisal, relaxation, effort, and seeking support) and 4 coping strategies organized within disengagement-oriented coping dimensions (DOC; i.e., behavioral disengagement, mental distraction, venting, and social distancing $)^{4}$. Correlations among the seven coping strategies that fall under the TOC dimension were all statistically significant for the academic $(r s>.21, p s<.05)$ and career domains $(r s>.24$, $p s<.05)$. Similarly, the correlations among the four coping strategies that fall under the DOC dimension were all statistically significant for the academic $(r s>.13, p s<.05)$ and career domains ( $r s>.40, p s<.05)$. Sample items for TOC strategies include "I put effort in my goal", "I try to picture myself successfully completing my goal", and "I try to manage my time". Sample items for DOC strategies include "I express my annoyance with my goal", "I divert my attention

\footnotetext{
${ }^{4}$ Information regarding the factor structure of our coping dimensions can be provided upon request.
} 
from my goal", and "I keep everyone at a distance". All items were rated using a scale from 1 (Does not correspond at all) to 5 (Corresponds totally). Mean scores were used as indicators for the latent variables of academic and career TOC and DOC and all four coping variables were modeled as single indicators of latent variables. Consistent with previous studies (e.g., Gaudreau et al., 2012), both coping dimensions had acceptable to good reliability for the academic (TOC, $\alpha$ $=.91 ; \mathrm{DOC}, \alpha=.82$ ) and career domains (TOC, $\alpha=.91 ; \mathrm{DOC}, \alpha=.83$ ).

\section{Overview of the Analyses}

Doubt and progress were examined as latent variables, whereas coping dimensions were examined as manifest variables due to their complex structure. This approach enabled us to significantly reduce the number of parameters. In order to adjust for measurement error, all four coping variables were modeled as single indicators of latent variables with loadings fixed at 1.0 and unique variances fixed to values that were computed using the following formula: (1reliability) * variance (see Williams \& O’Boyle, 2008) ${ }^{5}$. Structural equation modeling (SEM) using Mplus version 7.2 was used for the main analyses (Muthén \& Muthén, 2012). Standard errors and fit indices were corrected for non-normality using the full information maximum likelihood robust estimator (MLR).

First, a confirmatory factor analysis was performed to assess the suitability of the proposed measurement model and estimate error-free correlations between latent variables. Autocorrelated residuals of the same variable were freely estimated across domains. The fit of the model was tested using chi square and other fit indexes. The confirmatory fit index (CFI), Tucker-Lewis index (TLI), root mean square error of approximation (RMSEA), standardized

\footnotetext{
${ }^{5}$ Variance values were obtained from Mplus output, and reliability values were estimated using Cronbach's alpha.
} 
Root Mean Square Residuals Index (SRMR), and MLR chi-square statistic were used. Values of .95 or higher for CFI and TLI as well as values smaller than .06 for RMSEA were deemed a good fit (Hu \& Bentler, 1999).

Second, two structural models were tested. In the first structural model, we tested withindomain effects between coping and goal progress. We estimated the paths from academic coping to academic goal progress and the paths from career coping to career goal progress. In the second structural model, we tested the same model with four additional spillover paths. We estimated the cross-domain paths from academic coping to career goal progress and from career coping to academic goal progress. Third, to test the mediation hypotheses, the total effect of career doubt on both academic and career goal progress (i.e., effect without controlling for coping) was divided into a direct effect (i.e., effect of career doubt when controlling for coping) and an indirect effect (i.e., part of the relationship between doubt and goal progress explained by coping). The statistical significance of each indirect effect was estimated using 5000 bootstrapped resamples and 95\% bias corrected bootstrapped confidence intervals (Preacher \& Hayes, 2008). Nested models were compared using the scaled chi-square difference test $\Delta$ MLR $\chi^{2}$, based on the Satorra-Bentler formula (Satorra \& Bentler, 2001), calculated using an online calculator (http://www.uoguelph.ca/ scolwell/difftest.html). Finally, we tested differences in latent means and structural path coefficients for goal domains and for first- and fourth-year students.

\section{Results}

\section{Preliminary Analyses}

Seven participants were excluded due to missing data on all variables of interest. We used the Mahalanobis distance critical cut-off value $\left(\chi^{2}=49.73, d f=23, p<.001\right)$ to identify potential multivariate outlying cases. Twelve participants were deemed to be multivariate outliers and were 
excluded from the subsequent analyses. A total of 234 undergraduate students were retained for subsequent analyses.

\section{Measurement Model}

First, a confirmatory factor analysis was performed to assess the suitability of the proposed measurement model. As shown in Table 1, the measurement model provided a good fit, thus indicating that the specified model properly fit the data for both academic and career domains. Correlations between latent variables are reported in Table 2.

\section{Structural Models}

In the first structural model, we tested only the within-domain paths between coping and goal progress. As shown in Table 1, this model provided a good fit to the data. In the second structural model, we added four spillover paths from academic coping to career goal progress and from career coping to academic goal progress. These additions did not improve the fit of the model and none of the four spillover paths reached statistical significance. The first structural model was therefore retained as the best fitting model as it was more parsimonious. Standardized path coefficients of this model are reported in Figure 1.

For the academic domain, there was a non-significant total effect $(\beta=-.12, p>.05,95 \%$ BcaCI $[-.253, .019])$ and a non-significant direct effect $(\beta=.03, p>.05,95 \%$ BcaCI $[-.191, .246])$ between career doubt and progress. Career doubt was negatively associated to academic TOC and positively associated with academic DOC. Academic TOC was positively associated to academic goal progress, whereas academic DOC was not. The indirect effect through academic TOC was significant $(\beta=-.11, p<.05,95 \%$ BcaCI $[-.188,-.021])$ whereas the indirect effect through DOC

was non-significant $(\beta=-.04, p>.05,95 \%$ BcaCI $[-.166, .088])$. Overall, academic TOC was significant mediator of the association between career doubt and academic goal progress. 
For the career domain, there was a significant total effect $(\beta=-.24, p<.05,95 \%$ BcaCI [$.379,-.102])$, and a non-significant direct effect $(\beta=-.18, p>.05,95 \%$ BcaCI [-.383, .031]) between career doubt and progress. Career doubt was negatively associated to career TOC and positively associated to career DOC. Career TOC was positively associated to career goal progress, whereas career DOC was not. The indirect effect through career TOC was significant $(\beta=-.12, p$ $<.05,95 \%$ BcaCI [-.192, -.043]) whereas the indirect effect through DOC was non-significant $(\beta$ $=.05, p>.05,95 \%$ BcaCI $[-.077, .183])$. Overall, career TOC was a significantly mediator of the association between career doubt and career goal progress.

\section{Complementary Analyses}

Domain differences. We tested differences in latent means and structural path coefficients for the academic and career domains (Jung \& Yoon, 2016). Based on the measurement model, we first compared the latent means of coping and goal progress across academic and career domains. Results indicated no significant difference in the latent means of TOC $(b=-.05, \mathrm{SE}=.03, p>.05)$ and goal progress $(b=-002, \mathrm{SE}=.076, p>.05)$ across domains. In contrast, the latent mean of career DOC $(b=-.29, \mathrm{SE}=.03, p<.001)$ was significantly lower than that of academic DOC, indicating that students, on average, used DOC to a lesser extent in the career domain compared to the academic domain. We further tested the invariance of the structural path coefficients between academic and career domains. Results indicated that the five paths between the latent variables in the structural model did not significantly differ across domains $(p s>.10)$.

Group differences. We performed additional multi-group analyses by splitting our sample into groups of first $(n=153)$ and fourth year students $(n=81)$ in order to create new parameters that allowed us to test differences in latent means and structural path coefficients. First, the mean of goal progress for the academic domain was significantly higher for the group 
of fourth year students $(\mathrm{b}=-.50, \mathrm{SE}=.17, \mathrm{p}<.05)$, whereas the six other latent variables did not significantly differ across groups ( $\mathrm{ps}>.09$ ). Second, the five paths between the latent variables in the structural model did not significantly differ across groups (ps $>.05)$. Overall, these findings indicate that although a few differences were to be expected, the parameter estimates reported in our main analyses can be generalized to both subgroups of students in this sample.

\section{Discussion}

Pursuing academic and career goals are important developmental tasks for university students. In this study, we investigated the mediating role of academic and career coping in the association between career doubt and goal progress for both academic and career goals. As expected, career doubt was negatively associated to academic task-oriented coping, which was positively associated to academic goal progress. Similarly, career doubt was negatively associated to career task-oriented coping, which was positively related to career goal progress. Interestingly, task-oriented coping explained a significant portion of the relation between career doubt and goal progress in both the academic and career goal domains. In contrast, career doubt was positively associated with disengagement-oriented coping, but disengagement-oriented coping was not significantly associated to goal progress in both the academic and career goal domains. Overall, the present study revealed that career doubt plays a role in how university students are coping with the pursuit of both their academic and career goals, while only taskoriented coping relates to the progress they are making in those pursuits.

\section{Toward a Dual Domain Model of Goal Pursuit}

According to our findings, students who experienced lower levels of career doubt were more likely to engage in active coping strategies and progress toward the achievement of both their academic and career self-set goals. These findings lend support to assumptions made by theories 
of self-regulation (e.g., Bandura, 1994; Latham \& Locke, 1991; Judge, Bono, Erez, \& Locke, 2005), such that people's beliefs about their goals are likely to determine how they will approach challenges associated to those goals and influence both goal pursuit processes and achievement (Carver \& Scheier, 2001; Bandura, 1994; Locke \& Latham, 1990). Career doubt which, by definition, reflects uncertainty with regards to career choices and commitments (Porfeli \& Savickas, 2012), can therefore be associated with goal progress through a multitude of coping strategies. As such, when students experience less doubt about their career choices, they may be more likely to remain engaged in the face of adversity and invest the task-oriented coping efforts likely to be associated with successful academic and career strivings. It is important to note that, although most of the hypothesized paths are consistent with the data, the processes in our dualdomain model should be seen as transactional and likely to operate through reciprocal determinism. However, the cross-sectional design of this study prevented us from examining the potentially existing bidirectional associations nested in our model. Making sufficient progress on either academic or career goals could reduce subsequent experiences of career doubt just as much as goalrelated failures or blockage could lead to subsequent disengagement-oriented coping across both academic and career domains. Many such empirical questions remain to be answered but the current study provided the needed information that will enable subsequent research endeavours to clarify whether career doubt influences goal progress, goal progress influences career doubt, or both. As such, future research should use cross-lagged longitudinal designs (Cole \& Maxwell, 2003) and perhaps even sophisticated experimental designs to manipulate the plausible predictors and mediators nested in our dual-domain model (Pirlott \& MacKinnon, 2016).

In addition to lending support to assumptions made by theories of self-regulation, our findings also highlighted the relevance of a dual-domain framework in which both the academic 
and career pursuits of students are taken into consideration. Specifically, feelings toward career choices seem to be associated with coping and goal progress not only in the career domain but also in the academic domain. These findings are supported by the social cognitive theory of career development, which argues for the interdependence of the processes involved in academic and career strivings (Lent, Brown, \& Hackett, 2002). Accordingly, proximal goals can be instrumental to the pursuit of broader and more distal goals, and distal career goals can hold motivational relevance for the pursuit of more immediate, albeit related academic goals (Bandura, 1989; Kruglanski et al., 2002; Latham \& Locke, 1991; Stock \& Cervone, 1990). Students who experience more doubt regarding their career choices may be more likely to pursue their academic and career goals in a passive and disengaged manner as it becomes more difficult for them project themselves into the future. Students who experience less doubt regarding their career choices, in contrast, may be more likely to project themselves into the future and set meaningful academic and career goals. Such goals can provide students with a sense of purpose and motivate them to engage in the taskoriented coping strategies relevant to the successful management of day-to-day challenges and pursuits (Miller \& Brickman, 2004; Park \& Folkman, 1997). For example, a student's goal of becoming an architect is likely helped by his or her ability to attend class, learn the proper material, request help when necessary, and plan out the various assignments. As such, the student is taking the specific steps required to achieve the larger goal of becoming an architect by investing the necessary resources and attaining the necessary level of performance in his or her more immediate academic pursuits. In that regard, distal goals hold a motivational relevance by fostering the active pursuit of instrumental goals (Shah \& Kruglanski, 2000).

It is noteworthy to report that career doubt was associated significantly and positively to disengagement-oriented coping, but that disengagement-oriented coping was not associated 
significantly to goal progress. Such results, albeit surprising, are consistent with the results of other studies conducted with university students. We advance three possible explanations for this finding. First, task-oriented coping appears to be the predominant coping of university students to deal with both their academic and career-related goals (see Table 2). In such context, it appears unlikely that many students would only use disengagement-oriented coping to manage the demands of their goals. The combined usage of disengagement-oriented coping with task-oriented coping by a majority of students would potentially explicate why disengagement does not improve nor worsen the likelihood of making progress on personal goals. Second, students for whom we would be more likely to observe a significant negative relationship between disengagement-oriented coping and goal progress may no longer be enrolled at the university. Indeed, a recurrent and predominant usage of disengagement-oriented coping may impede students' capacity to persevere through the many challenges of their academic lives. Hence, those students who predominantly use disengagement-oriented strategies, without task-oriented strategies, may already have withdrawn from university. Finally, sporadic usage of disengagement-oriented coping may be required to help students to recover and momentarily distance and distract themselves from their school and careerrelated projects. Proper sequencing of periods of active task-oriented engagement followed by sporadic bouts of disengagement might be required to help students maintain the needed vigor and dedication to successfully handle the pursuit of their academic and career goals. Studying how students go through coping episodes of task engagement, disengagement, and task re-engagement using intensive longitudinal designs (e.g., daily diaries, weekly diaries) appears warranted to shed light on the complex relationship between disengagement-oriented coping and goal progress.

Moreover, the present findings provide empirical support for the parallel within-domain processes that relate career doubt to academic and career goal progress (Lent et al., 1994). That is, 
the coping mechanisms (i.e., academic- and career-related coping) associated to career doubt and goal progress operated in a similar way in both domains. Task-oriented coping seems to be an important personal resource for students in the pursuit of both their academic and career goals. Importantly, research suggests that the strategies that help students succeed in the pursuit of their academic and career goals (e.g., task-oriented coping) can also act as central personal resources for psychological health, coping, and performance at work (Boudrias et al., 2011; Christian, Garza, \& Slaughter, 2011; Welbourne, Eggerth, Hartley, Andrew, \& Sanchez, 2007). These coping strategies could therefore prove to be important personal skills that transfer from university to work and help newcomers succeed and adapt to their new achievement setting. Given that similar coping skills relate to adjustment and achievement outcomes in university and at work, longitudinal research is needed to examine coping skill development and the possible explanations for how, when, and under what conditions these skills develop in university students. On the basis of those results, research will need to determine whether (and how) institutions should focus their interventions to promote the transferability of these skills to help students succeed not only in school, but also in the work environment later on (Gould \& Carson, 2008; Pirlott \& MacKinnon, 2016).

\section{Limitations and Future Directions}

This study relied on a cross-sectional design that prevented us from making strong and definitive inferences about the direction of the relationship between the antecedent, mediator, and outcome variables included in our model. Nonetheless, we believe that cross-sectional analyses can serve to lay the foundation for future studies on the same topic, as long as the findings are interpreted with caution. As such, our proposed cross-sectional model should be interpreted as a stepping stone before looking at more complex and costly longitudinal models for which at least three-time points would be needed to truly infer directional and mediation effects (Maxwell \& 
Cole, 2003). Such a longitudinal study would enable us to establish whether career doubt influences coping and progress in the proposed sequence. It would also enable us to consider the potential feedback loop between goal progress and career doubt, in which case slower progress could result in greater doubt about career goals over time (Brandstätter \& Schüler, 2013; Carver \& Scheier, 2000; Hall, Sampasivam, Ruis, \& Ranellucci, 2016; Ghassemi, Bernecker, Herrmann, \& Brandstätter, 2017). Indeed, it is important to consider that the proposed sequence of relationships may in fact be reversed or reciprocal in nature, as advocated by theories of selfregulation (e.g., Bandura, 1991; Carver \& Scheier, 1990; 2000). Nonetheless, in accordance with our findings, these same theories propose that personal goals relate to distinct outcomes depending on the coping strategies used during the goal striving process (e.g., Brdar, Rijavec, \& Loncaric, 2006; Schellenberg \& Bailis, 2015; Gaudreau, Carraro, \& Miranda, 2012). Hence although our findings are cross-sectional, the present study contributes to the literature by providing a novel understanding of the potential underlying mechanisms and overlapping nature of academic and career goal pursuits. More complex longitudinal designs are needed to test our proposed model in light of potential reciprocal effects.

Aside from the points raised above, we used a unidimensional measure of career doubt. Doubt about career choices is arguably a multifaceted psychological experience that can take various degrees and forms for different people. Research on identity development offers a good example of the intricate complexities of career goals (Meijers, 1998). Career doubt may reflect different sources of uncertainties, such as lack of self- and career exploration (Chickering \& Reisser, 1993), or internal and external pressures to pursue a career different from the one chosen (Sheldon \& Elliot, 1999). Furthermore, career doubt and career certainty may not be perfect antonyms insofar as students can alternate between being certain about some aspects of their career 
goals while remaining unsettled about other characteristics of their career pursuits. Similarly, students who make commitments without exploring alternatives or students who select their career path based solely on their parents' beliefs (i.e., identity foreclosure; Brisbin \& Savickas, 1994) may still exhibit a mixture of career certainty and doubt. Further, theories of self-regulation propose that doubt can be understood as the opposite of self-efficacy (Bandura, 1994; Carver \& Scheier, 2001; Zimmerman \& Schunk, 2008). Hence, future research should include career doubt, career certainty, and self-efficacy as distinct variables in our dual-domain model to better understand their respective roles.

Moreover, our data was collected with the use of self-report measures, which could have been affected by the social desirability and introspection capabilities of our sample of university students. This method nonetheless allowed us to measure constructs that would have been otherwise difficult to obtain with behavioral or physiological assessments. Although many studies rely on objective measures of academic outcomes, such as grades, to evaluate all students on similar grounds, we believe that goal progress is a self-report construct that better captures the subjective component of success, something that is truly unique to every individual. For example, two students with the same grade (e.g., B) may have totally attained or totally unattained their academic goal, thus leading to increases in positive affect and negative affect, respectively (Wiese, 2007). Further, undergraduate students are not the only ones who pursue both academic and career goals. Given that career doubt may be expressed differently in different populations, future research should consider our model among individuals other than undergraduate students, such as high school, vocational school, or graduate students. Hence, given the novelty of our findings, future research is needed to test our model under various conditions.

\section{Practical Implications}


The findings of the present study are of importance for university students and postsecondary institutions as they illustrate how career doubt can relate to lower usage of task-oriented coping strategies and achievement in the pursuit of both academic and career goals. As stated by the social cognitive career theory (Lent et al., 2002) and Chickering's identity development theory (Chickering \& Reisser, 1993), self-exploration, self-knowledge, and coping are pivotal processes that promote the academic and career success of students. Indeed, successful work entry depends on how well students prepare themselves not only immediately before this important life transition but also early on during their post-secondary education (Lent et al., 1994; Nurmi et al., 2002). Our findings support the theory and point to how important it can be for students to develop academic and career interests, form linkages between interests and career-related goals, translate these goals into actions, develop academic and work skills, and manage the barriers that affect the pursuit of desired academic and career outcomes. Although these processes are ongoing, the findings of the present study support these propositions by illustrating the link between career doubt and academic and career goal progress, as well as the role of different coping strategies during the pursuit of such goals. Pursuing personal goals and coping with the demands associated with these goals are therefore critical mechanisms through which students exercise personal agency and guide their own academic and career behavior and progress (Lent et al., 1994)

Taken together, these findings provide new information to inform the development of early interventions designed to promote the management of career doubt and the promotion of task-oriented coping efforts to handle both academic and career-related demands. In fact, coping has become the focus of much research as it stands at the heart of student persistence and has been shown to relate positively to academic retention (DeBerard, Spielmans, \& Julka, 2004) and negatively to burnout (Ben-Zur \& Michael, 2007; De Rijk, Blanc, Schaufeli, \& De Jonge, 1998; 
Sabagh, Hall, \& Saroyan, 2018). Hence, students who experience less doubt regarding their career are more likely to actively manage their academic pursuits and may not only be more likely to perform and adjust to university, but also to their work environment later on. Whether interventions should focus on career doubt, task-oriented coping, or both is a question that will require further empirical investigation. Similarly, intervention research should examine shortterm educational and long-term career effects in order to inform the development and implementation of evidence-based principles to promote academic retention, facilitate the transition into the workforce, and ultimately foster long-term work engagement and satisfaction. Creating bridges between educational and work psychology will be required to help postsecondary institutions and their service providers to promote a successful transition from postsecondary education to the job market.

\section{Conclusion}

The present study was among the first to examine academic pursuits in the broader context of career doubt. Simply considering the academic and career goals of a student, independently, is not sufficient to grasp the whole picture of personal strivings as individuals rarely invest all their efforts on a single goal and rarely pursue goals that are completely independent from one another. Hence given that university is, for most, a full-time challenge that prepares students for life outside of university, research that focuses too closely on academic success might forget that human development is a holistic process that involves various interrelated goals (Heckhausen et al., 2010). Our dual-domain approach to career doubt therefore sets the stage for the adoption of a more comprehensive conceptual framework that provides insight into students' experiences and the factors that could facilitate their transition to work life. 


\section{References}

Akkermans, J., Nykänen, M., \& Vuori, J. (2015). Practice makes perfect? Antecedents and consequences of an adaptive school-to-work transition. In J. Vuori, R. Blonk, \& R. H. Price (Eds.), Sustainable Working Lives (pp. 65-86). Dordrecht: Springer Netherlands.

Aldwin, C. M., Skinner, E. A., Taylor, A., \& Zimmer-Gembeck, M. J. (2011). Coping and selfregulation across the lifespan. In K. Fingerman, C. Berg, T. Antonucci, J. Smith, \& T. Antonucci (Eds.), Handbook of lifespan development (pp. 563-590). New York: Springer.

Amiot, C. E., Blanchard, C. M., \& Gaudreau, P. (2008). The self in change: A longitudinal investigation of coping and self-determination processes. Self and Identity, 7, 204-224. doi: $10.1080 / 15298860701580793$

Amiot, C. E., Blanchard, C. M., Gaudreau, P., Amiot, C. E., Blanchard, C. M., \& Gaudreau, P. (2004). Self-determination, coping, and goal attainment in sport. Journal of Sport and Exercise Psychology, 26, 396-411. doi: 10.1123/jsep.26.3.396

Amiot, C. E., de la Sablonnière, R., Terry, D. J., \& Smith, J. R. (2007). Integration of social identities in the self: Toward a cognitive-developmental model. Personality and Social Psychology Review, 11, 364-388. doi:10.1177/1088868307304091

Arnett, J. J. (2000). Emerging adulthood: A theory of development from the late teens through the twenties. American Psychologist, 55, 469-480. doi: 10.1037//0003-066X.55.5.469

Bandura, A. (1989). Human agency in social cognitive theory. American Psychologist, 44, 11751184. doi: 10.1037/0003-066X.44.9.1175

Bandura, A. (1994). Self-efficacy. In R. J. Corsini (Ed.), Encyclopedia of psychology (2nd ed., Vol. 3, pp. 368-369). New York: Wiley. 
Ben-Zur, H., \& Michael, K. (2007). Burnout, Social Support, and Coping at Work Among Social Workers, Psychologists, and Nurses: The Role of Challenge/Control Appraisals. Social Work in Health Care, 45, 63-82. doi: 10.1300/J010v45n04_04

Boudrias, J.-S., Desrumaux, P., Gaudreau, P., Nelson, K., Brunet, L., \& Savoie, A. (2011). Modeling the experience of psychological health at work: The role of personal resources, social-organizational resources, and job demands. International Journal of Stress Management, 18, 372-395. doi: 10.1037/a0025353

Brandstätter, V., \& Herrmann, M. (2016). Goal disengagement in emerging adulthood: The adaptive potential of action crises. International Journal of Behavioral Development, 40, 117-125. doi: 10.1177/0165025415597550

Brisbin, L. A., \& Savickas, M. L. (1994). Career indecision scales do not measure foreclosure. Journal of Career Assessment, 2, 352-363. doi: 10.1177/106907279400200403

Brown, S. P., Westbrook, R. A., \& Challagalla, G. (2005). Good cope, bad cope: adaptive and maladaptive coping strategies following a critical negative work event. Journal of Applied Psychology, 90, 792-798. doi: 10.1037/0021-9010.90.4.792

Carraro, N., \& Gaudreau, P. (2011). Implementation planning as a pathway between goal motivation and goal progress for academic and physical activity goals. Journal of Applied Social Psychology, 41, 1835-1856. doi: 10.1111/j.1559-1816.2011.00795.x

Carraro, N., \& Gaudreau, P. (2015). Predicting physical activity outcomes during episodes of academic goal conflict. Personality and Social Psychology Bulletin, 41, 1291-1305. doi: $10.1177 / 0146167215594121$

Carver, C. S. (1998). On the self-regulation of behavior. Cambridge, UK ; New York, NY, USA: Cambridge University Press. 
Carver, C. S., \& Connor-Smith, J. (2010). Personality and coping. Annual Review of Psychology, 61, 679-704. doi: 10.1146/annurev.psych.093008.100352

Carver, C. S., \& Scheier, M. F. (2001). Optimism, pessimism, and self-regulation. In Optimism \& pessimism: Implications for theory, research, and practice (pp. 31-51). Washington, DC, US: American Psychological Association. doi:10.1037/10385-002

Carver, C. S., \& Scheier, M. F. (2000). On the structure of behavioral self-regulation. In P. R. Pintrich \& M. Zeidner (Eds.), Handbook of Self-Regulation (pp. 41-84). San Diego: Academic Press.

Chickering, A. W., \& Reisser, L. (1993). Education and identity (2nd ed.). San Francisco: Jossey-Bass.

Christian, M. S., Garza, A. S., \& Slaughter, J. E. (2011). Work engagement: A quantitative review and test of its relations with task and contextual performance. Personnel Psychology, 64, 89-136. doi: 10.1111/j.1744-6570.2010.01203.x

Cole, D. A., Maxwell, S. E. (2003). Testing mediational models with longitudinal data: Questions and tips in the use of structural equation modeling. Journal of Abnormal Psychology, 112, 558-577. doi:10.1037/0021-843X.112.4.558

Compas, B. E., Jaser, S. S., Dunbar, J. P., Watson, K. H., Bettis, A. H., Gruhn, M. A., \& Williams, E. K. (2014). Coping and emotion regulation from childhood to early adulthood: Points of convergence and divergence. Australian Journal of Psychology, 7181. doi:10.1111/ajpy.12043

Cuseo, J. (2005). Decided, undecided, and in transition: Implications for academic advisement, career counseling, and student retention. In R. S. Feldman (Ed.), Improving the First Year of College: Research and Practice, (pp. 27-50). Mahwah, NJ: Erlbaum. 
DeBerard, M. S., Spielmans, G., \& Julka, D. (2004). Predictors of academic achievement and retention among college freshmen: A longitudinal study. College Student Journal, 38, 66-80.

De Rijk, A. E., Blanc, P. M. L., Schaufeli, W. B., \& De Jonge, J. (1998). Active coping and need for control as moderators of the job demand-control model: Effects on burnout. Journal of Occupational and Organizational Psychology, 71, 1-18. doi: 10.1111/j.20448325.1998.tb00658.x

Dietrich, J., Jokisaari, M., \& Nurmi, J.-E. (2012). Work-related goal appraisals and stress during the transition from education to work. Journal of Vocational Behavior, 80, 82-92. doi: 10.1016/j.jvb.2011.07.004

Edwards, J. M., \& Trimble, K. (1992). Anxiety, coping and academic performance. Anxiety, Stress \& Coping, 5, 337-350. doi: 10.1080/10615809208248370

Erikson, E. H. (1968). Identity, youth, and crisis (1st ed.). New York: W. W. Norton.

Fugate, M., Kinicki, A. J., \& Ashforth, B. E. (2004). Employability: A psycho-social construct, its dimensions, and applications. Journal of Vocational Behavior, 65, 14-38. doi: 10.1016/j.jvb.2003.10.005

Gaudreau, P., Carraro, N., \& Miranda, D. (2012). From goal motivation to goal progress: the mediating role of coping in the Self-Concordance Model. Anxiety, Stress \& Coping, 25, 507-528. doi: 10.1080/10615806.2011.628015

Ghassemi, M., Bernecker, K., Herrmann, M., \& Brandstätter, V. (2017). The Process of Disengagement from Personal Goals: Reciprocal Influences Between the Experience of Action Crisis and Appraisals of Goal Desirability and Attainability. Personality and Social Psychology Bulletin, 43, 524-537. doi: 10.1177/0146167216689052 
Gollwitzer, P. M., \& Sheeran, P. (2006). Implementation Intentions and Goal Achievement: A Meta-analysis of Effects and Processes. In Advances in Experimental Social Psychology (Vol. 38, pp. 69-119). Academic Press. doi:10.1016/S0065-2601(06)38002-1

Gordon, V. N., \& Steele, G. E. (2015). The undecided college student: An academic and career advising challenge (4th ed.). Springfield, IL: Charles C. Thomas.

Gould, D., \& Carson, S. (2008). Life skills development through sport: current status and future directions. International Review of Sport and Exercise Psychology, 1, 58-78. doi: $10.1080 / 17509840701834573$

Hall, N. C., Sampasivam, L., Muis, K. R., \& Ranellucci, J. (2016). Achievement goals and emotions: The mediational roles of perceived progress, control, and value. British Journal of Educational Psychology, 86, 313-330. doi:10.1111/bjep.12108

Hancock, G. R. \& Mueller, R. O. (2001). Factor analysis and latent structure: Confirmatory factor analysis. International encyclopedia of the social and behavioral sciences, 52395244.

Heckhausen, J., Wrosch, C., \& Schulz, R. (2010). A Motivational Theory of Life-Span Development. Psychological Review, 117, 32-60. doi:10.1037/a0017668

Higgins, E. T., Loeb, I., \& Ruble, D. N. (1995). The four A's of life transition effects: Attention, accessibility, adaptation, and adjustment. Social Cognition, 13, 215-242. doi: 10.1521/soco.1995.13.3.215

Hu, L., \& Bentler, P. M. (1999). Cutoff criteria for fit indexes in covariance structure analysis: Conventional criteria versus new alternatives. Structural Equation Modeling: A Multidisciplinary Journal, 6, 1-55. doi: 10.1080/10705519909540118 
Judge, T. A., Bono, J. E., Erez, A., \& Locke, E. A. (2005). Core self-evaluations and job and life Satisfaction: the role of self-concordance and goal attainment. Journal of Applied Psychology, 90, 257-268. doi: 10.1037/0021-9010.90.2.257

Jung, E., \& Yoon, M. (2016). Comparisons of three empirical methods for partial factorial invariance: Forward, backward, and factor-ratio tests. Structural Equation Modeling: A Multidisciplinary Journal, 23, 567-584. doi:10.1080/10705511.2015.1138092

Kahn, J. H., Nauta, M. M., Gailbreath, R. D., Tipps, J., \& Chartrand, J. M. (2002). The Utility of Career and Personality Assessment in Predicting Academic Progress, 10, 3-23. doi: $10.1177 / 1069072702010001001$

Koestner, R., Lekes, N., Powers, T. A., \& Chicoine, E. (2002). Attaining personal goals: selfconcordance plus implementation intentions equals success. Journal of Personality and Social Psychology, 83, 231-244. doi:10.1037/0022-3514.83.1.231

Koestner, R., Otis, N., Powers, T. A., Pelletier, L., \& Gagnon, H. (2008). Autonomous motivation, controlled motivation, and goal progress. Journal of Personality, 76, 12011230. doi: 10.1111/j.1467-6494.2008.00519.x

Körner, A., Lechner, C. M., Pavlova, M. K., \& Silbereisen, R. K. (2015). Goal engagement in coping with occupational uncertainty predicts favorable career-related outcomes. Journal of Vocational Behavior, 88, 174-184. doi: 10.1016/j.jvb.2015.03.001

Kruglanski, A. W., Shah, J. Y., Fishbach, A., Friedman, R., Woo Young Chun, D., \& SleethKeppler, D. (2002). A theory of goal systems. Advances in Experimental Social Psychology, 34, 331-378. doi: 10.1016/S0065-2601(02)80008-9 
Latham, G. P., \& Locke, E. A. (1991). Self-regulation through goal setting. Organizational Behavior and Human Decision Processes, 50, 212-247. doi: 10.1016/07495978(91)90021-K

Lazarus, R. S. (2006). Stress and emotion: A new synthesis. New York: Springer Pub. Co.

Lazarus, R. S., \& Folkman, S. (1984). Stress, appraisal, and coping. New York: Springer.

Lent, R. W., Brown, S. D., \& Hackett, G. (1994). Toward a unifying social cognitive theory of career and academic interest, choice, and performance, 45, 79-122. doi: 10.1006/jvbe.1994.1027

Lent, R. W., Brown, S. D., \& Hackett, G. (2002). Social cognitive career theory. In D. Brown (Ed.), Career choice and development (4th ed., pp. 255-311). San Francisco, CA: Jossey-Bass.

Locke, E. A. (1996). Motivation through conscious goal setting. Applied and Preventive Psychology, 5, 117-124. doi: 10.1016/S0962-1849(96)80005-9

Locke, E. A., \& Latham, G. P. (1990). Work motivation and satisfaction: Light at the end of the tunnel. Psychological Science, 1, 240-246. doi: 10.1111/j.1467-9280.1990.tb00207.x

Locke, E. A., Frederick, E., Lee, C., \& Bobko, P. (1984). Effect of self-efficacy, goals, and task strategies on task performance. Journal of Applied Psychology, 69, 241-251. doi: $10.1037 / 0021-9010.69 .2 .241$

Lunneborg, P. W. (1975). Interest differentiation in high school and vocational indecision in college. Journal of Vocational Behavior, 7, 297-303. doi: 10.1016/00018791(75)90071-8

Lunneborg, P. W. (1976). Vocational indecision in college graduates. Journal of Vocational Behavior, 23, 402-404. doi: 10.1037/0022-0167.23.4.402 
MacCann, C., Fogarty, G. J., Zeidner, M., \& Roberts, R. D. (2011). Coping mediates the relationship between emotional intelligence (EI) and academic achievement. Contemporary Educational Psychology, 36, 60-70. doi: 10.1016/j.cedpsych.2010.11.002

Meijers, F. (1998). The development of a career identity. International Journal for the Advancement of Counselling, 20, 191-207. doi: 10.1023/A:1005399417256

Miller, R., \& Brickman, S. (2004). A model of future-oriented motivation and self-regulation. Educational Psychology Review, 16, 9-33. doi: 10.1023/B:EDPR.0000012343.96370.39

Muthén, L., \& Muthén, B. (2012). Mplus user's guide. Version 7. Los Angeles, CA: Muthén \& Muthén.

Nurmi, J. E., \& Salmela-Aro, K. (2002). Goal Construction, Reconstruction and Depressive Symptoms in a Life-Span Context: The Transition from School to Work. Journal of personality, 70, 385-420. doi: 10.1111/1467-6494.05009

Nurmi, J.-E., Salmela-Aro, K., \& Koivisto, P. (2002). Goal importance and related achievement beliefs and emotions during the transition from vocational school to work: Antecedents and consequences. Journal of Vocational Behavior, 60, 241-61. doi: 10.1006/jvbe. 2001.1866

O’Hare, M. M., \& Beutell, N. J. (1987). Sex differences in coping with career decision-making. Journal of Vocational Behavior, 31, 174-181. doi: 10.1016/0001-8791(87)90055-8

O’Hare, M. M., \& Tamburri, E. (1986). Coping as a moderator of the relation between anxiety and career decision-making. Journal of Counseling Psychology, 33, 255-264. doi: 10.1037/0022-0167.33.3.255 
Ozer, E. M., \& Bandura, A. (1990). Mechanisms governing empowerment effects: a self-efficacy analysis. Journal of personality and social psychology, 58, 472. doi: 10.1037//00223514.58.3.472

Park, C. L., \& Folkman, S. (1997). Meaning in the context of stress and coping, 1, 115-144. doi: $10.1037 / 1089-2680.1 \cdot 2.115$

Pirlott, A. G., \& MacKinnon, D. P. (2016). Design approaches to experimental mediation. Journal of Experimental Social Psychology, 66, 29-38. doi:10.1016/j.jesp.2015.09.012

Porfeli, E. J., Lee, B., Vondracek, F. W., \& Weigold, I. K. (2011). A multi-dimensional measure of vocational identity status. Journal of Adolescence, 34, 853-871. doi:

10.1016/j.adolescence.2011.02.001

Porfeli, E. J., \& Savickas, M. L. (2012). Career adapt-Abilities Scale-USA Form: Psychometric properties and relation to vocational identity. Journal of Vocational Behavior, 80, 748753. doi: 10.1016/j.jvb.2012.01.009

Praskova, A., Creed, P. A., \& Hood, M. (2014). Self-regulatory processes mediating between career calling and perceived employability and life satisfaction in emerging adults. Journal of Career Development, 42, 86-101. doi: 10.1177/0894845314541517

Praskova, A., Creed, P. A., \& Hood, M. (2015). Career identity and the complex mediating relationships between career preparatory actions and career progress markers. Journal of Vocational Behavior, 87, 145-153. doi: 10.1016/j.jvb.2015.01.001

Preacher, K. J., \& Hayes, A. F. (2008). Asymptotic and resampling strategies for assessing and comparing indirect effects in multiple mediator models. Behavior Research Methods, 40, 879-891. doi: 10.3758/BRM.40.3.879 
Sabagh, Z., Hall, N. C., \& Saroyan, A. (2018). Antecedents, correlates and consequences of faculty burnout. Educational Research, 60, 131-156. doi:10.1080/00131881.2018.1461573

Saklofske, D. H., Austin, E. J., Mastoras, S. M., Beaton, L., \& Osborne, S. E. (2012). Relationships of personality, affect, emotional intelligence and coping with student stress and academic success: Different patterns of association for stress and success. Learning and Individual Differences, 22, 251-257. doi: 10.1016/j.lindif.2011.02.010

Satorra, A., \& Bentler, P. M. (2001). A scaled difference chi-square test statistic for moment structure analysis. Psychometrika, 66, 507-514.

Savickas, M. (1999). The transition from school to work: A developmental perspective. The Career Development Quarterly, 47, 326-336. doi: 10.1002/j.2161-0045.1999.tb00741.x

Schunk, D. H. (1990). Goal setting and self-efficacy during self-regulated learning. Educational Psychologist, 25, 71-86. doi: 10.1207/s15326985ep2501_6

Shah, J. Y., \& Kruglanski, A. W. (2000). Aspects of goal networks: Implications for selfregulation. In M. Boekaerts, P. R. Pintrich, \& M. Zeidner (Eds.), Handbook of SelfRegulation (pp. 85-110). San Diego: Academic Press.

Sheldon, K. M., \& Elliot, A. J. (1999). Goal striving, need satisfaction, and longitudinal wellbeing: the self-concordance model. Journal of Personality and Social Psychology, 76, 482. doi: $10.1037 / 0022-3514.76 .3 .482$

Shimazu, A., \& Schaufeli, W. (2007). Does Distraction Facilitate Problem-focused Coping with Job Stress? A 1 year Longitudinal Study. Journal of Behavioral Medicine, 30, 423-434. doi: $10.1007 / \mathrm{s} 10865-007-9109-4$ 
Shimazu, A., Schaufeli, W., \& Taris, T. (2010). How Does Workaholism Affect Worker Health and Performance? The Mediating Role of Coping. International Journal of Behavioral Medicine, 17, 154-160. doi: 10.1007/s12529-010-9077-х

Shulman, S., \& Nurmi, J.-E. (2010). Understanding emerging adulthood from a goal-setting perspective. New Directions for Child and Adolescent Development, 130, 1-11. doi: $10.1002 / \mathrm{cd} .277$

Skinner, E. A., \& Wellborn, J. G. (1997). Children's coping in the academic domain. In S. A. Wolchik \& I. N. Sandler (Eds.), Handbook of children's coping with common stressors: Linking theory and intervention (pp. 387-422). New York: Plenum Press.

Spitzer, T. M. (2000). Predictors of college success: A comparison of traditional and nontraditional age students. NASPA Journal, 38, 82-98. doi: 10.2202/1949-6605.1130

Stock, J., \& Cervone, D. (1990). Proximal goal-setting and self-regulatory processes. Cognitive Therapy and Research, 14, 483-498. doi: 10.1007/BF01172969

Struthers, C. W., Perry, R. P., \& Menec, V. H. (2000). An examination of the relationship among academic stress, coping, motivation, and performance in college. Research in Higher Education, 41, 581-592. doi: 10.1023/A:1007094931292

Sun, S. H., \& Frese, M. (2013). Multiple goal pursuit. In E. A. Locke \& G. P. Latham (Eds.), New developments in goal setting and task performance (pp. 177-194). New York, NY, US: Routledge/Taylor \& Francis Group.

Thompson, A. (2015). Coping with Stress in Undergraduate University Students: Development and Validation of the Coping Inventory for Academic Striving (CIAS) to Examine Key Educational Outcomes in Correlational and Experimental Studies. University of Ottawa, Ontario, Canada. doi:10.20381/ruor-4763 
van Dierendonck, D. (2015). The influence of planning, support and self-concordance on goal progress and job satisfaction. Evidence - Based HRM, 3, 206-221. doi:

\subsection{8/EBHRM-04-2014-0013}

Walters, G. D. (1982). Academic and personality correlates of career indecision in medical students entering training. Medical Education, 16, 314-318.

Welbourne, J. L., Eggerth, D., Hartley, T. A., Andrew, M. E., \& Sanchez, F. (2007). Coping strategies in the workplace: Relationships with attributional style and job satisfaction. Journal of Vocational Behavior, 70, 312-325. doi: 10.1016/j.jvb.2006.10.006

Wong, Z. Y., \& Kaur, D. (2018). The role of vocational identity development and motivational beliefs in undergraduates' student engagement. Counselling Psychology Quarterly, 31, 294-316. doi:10.1080/09515070.2017.1314249

Wiese, B. S. (2007). Successful pursuit of personal goals and subjective well-being. In B. R. Little, K. Salmela-Aro, \& S. D. Phillips (Eds.), Personal project pursuit: Goals, action, and human flourishing (pp. 301-328). Mahwah, NJ: Lawrence Erlbaum.

Wiese, B. S., \& Salmela-Aro, K. (2008). Goal conflict and facilitation as predictors of workfamily satisfaction and engagement. Journal of Vocational Behavior, 73, 490-497. doi: 10.1016/j.jvb.2008.09.007

Williams, L. J., \& O'Boyle Jr, E. H. (2008). Measurement models for linking latent variables and indicators: A review of human resource management research using parcels. Human Resource Management Review, 18, 233-242. doi: 10.1016/j.hrmr.2008.07.002

Xu, H., \& Tracey, T. J. G. (2014). The role of ambiguity tolerance in career decision-making. Journal of Vocational Behavior, 85, 18-26 doi: 10.1016/j.jvb.2014.04.001 
Zimmerman, B. J., Bandura, A., \& Martinez-Pons, M. (1992). Self-motivation for academic attainment: The role of self-efficacy beliefs and personal goal setting. American educational research journal, 29, 663-676. doi: 10.3102/00028312029003663

Zimmerman, B. J., \& Schunk, D. H. (2008). Motivation: An essential dimension of self-regulated learning. In Motivation and self-regulated learning: Theory, research, and applications (pp. 1-30). Mahwah, NJ, US: Lawrence Erlbaum Associates Publishers 
Table 1. Results of Structural Equation Models

\begin{tabular}{lllllllll}
\hline Models & $\chi^{2} \quad d f$ & CFI & TLI SRMR & $\begin{array}{c}\text { RMSEA } \\
90 \% \text { CI }\end{array}$ & Contrast & $\Delta d f$ & $\Delta \chi^{2}$ & $\Delta$ CFI \\
\hline
\end{tabular}

Measurement Model

$244.36^{* *} \quad 130 \quad .952 \quad 937 \quad .039 \quad .049-.073$

Structural Models

$\begin{array}{lllllllllllll}\text { 1. Within-Domain Effects } & 245.61^{* *} & 134 & .953 & .940 & .039 & .048-.071 & --- & --- & ---- & --- \\ & & & & & & & & & & & & \\ \text { 2. Within and Cross-Domain Effects } & 244.36^{* *} & 130 & .952 & .937 & .039 & .049-.073 & 2 \text { vs. } 1 & 4 & 2.05 & .001\end{array}$

Note. ${ }^{*} p<.05 .{ }^{* *} p<.01$. 
Table 2. Descriptive Statistics and Error-Free Correlations between Latent Variables

\begin{tabular}{|c|c|c|c|c|c|c|c|c|}
\hline & $M$ & $S D$ & 1. & 2. & 3. & 4. & 5. & 6. \\
\hline 1. Career doubt & 2.04 & 0.88 & - & & & & & \\
\hline \multicolumn{9}{|l|}{ Academic Domain } \\
\hline 2. TOC & 3.46 & 0.71 & $-.25^{* *}$ & - & & & & \\
\hline 3. DOC & 2.33 & 0.77 & $.58^{* *}$ & $-.16^{*}$ & - & & & \\
\hline 4. Goal progress & 4.68 & 1.28 & -.11 & $.42^{* *}$ & -.09 & - & & \\
\hline \multicolumn{9}{|l|}{ Career Domain } \\
\hline 5. TOC & 3.42 & 0.75 & $-.25^{* *}$ & $.86^{* *}$ & -.12 & $.36^{* *}$ & - & \\
\hline 6. DOC & 2.04 & 0.78 & $.65^{* *}$ & $-.15^{*}$ & $.82^{* *}$ & $-.16^{*}$ & -.12 & - \\
\hline 7. Goal progress & 4.28 & 1.37 & $-.24^{* *}$ & $.42^{* * *}$ & -.06 & $.39^{* *}$ & $.50^{* *}$ & -.11 \\
\hline
\end{tabular}

Note. TOC $=$ task-oriented coping; DOC $=$ disengagement-oriented coping. ${ }^{*} p<.05 .{ }^{* *} p<.01$. 


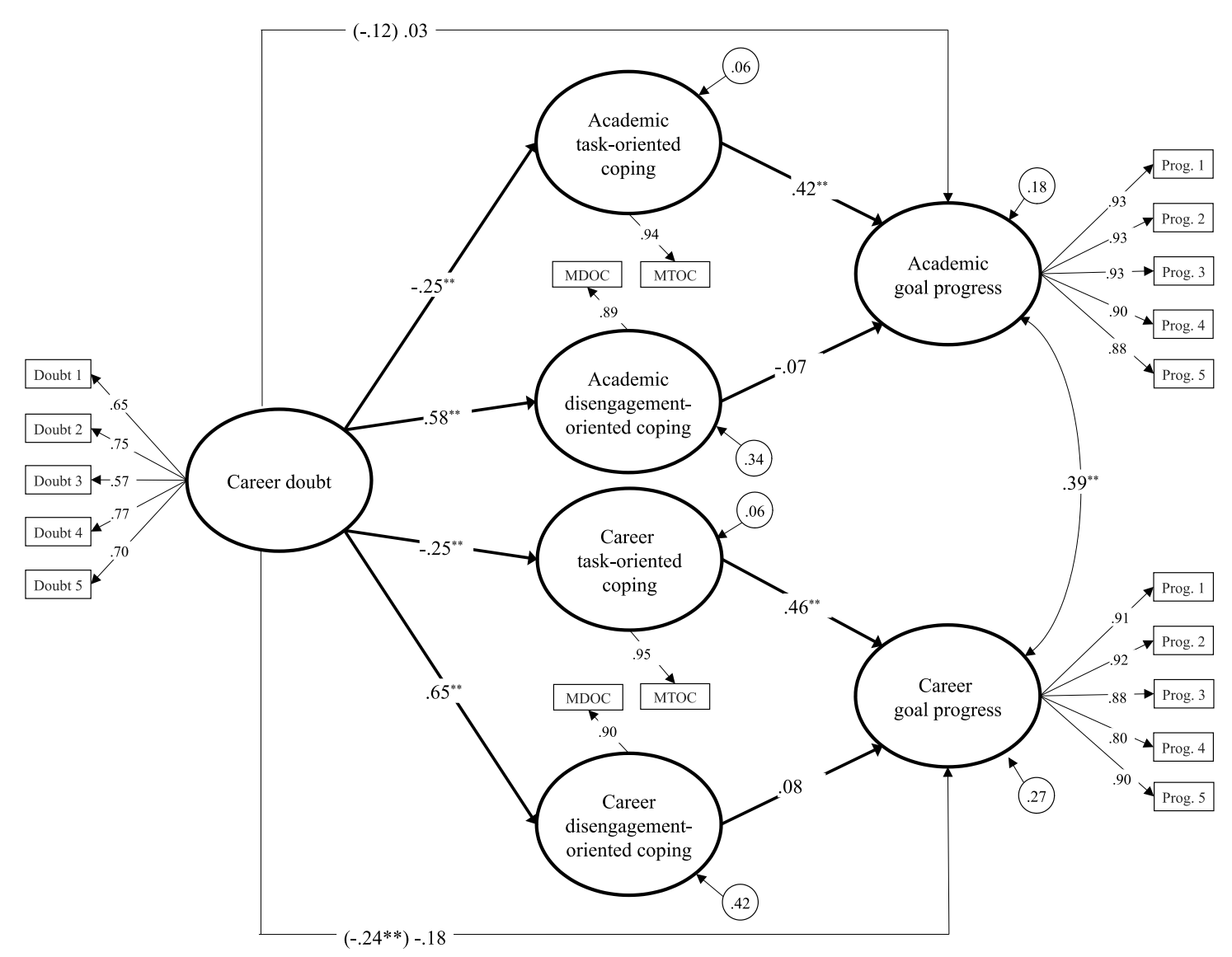

Figure 1. Within-domain structural model with standardized parameters. Total effects are presented in parentheses. For clarity, correlations between coping dimensions are not shown in this figure. $* p<.05, * * p<.01$. 